\title{
Oral health status \& treatment needs of patient attending anti retro-viral therapy among HIV patient in Government Medical College, Bhopal - A cross-sectional study
}

\author{
Vineesh Vishnu ${ }^{1}$, Vrinda Saxena ${ }^{2}$, Hemant Verma ${ }^{3}$, Vijayta Sharva ${ }^{4 *}$, Neha Jain ${ }^{5}$ and Mrinal Sathpathy \\ ${ }^{1}$ Senior Lecturer, Public Health Dentistry, Peoples Dental Academy, Bhopal (M.P.), India \\ ${ }^{2}$ Professor \& Head, Public Health Dentistry, Peoples Dental Academy, Bhopal (M.P.), India \\ ${ }^{3}$ Senior Medical Officer, Art Plus Cell, Gandhi Medical College, Bhopal, India \\ ${ }^{4}$ Reader, Public Health Dentistry, Peoples Dental Academy, Bhopal (M.P.), India \\ ${ }^{5}$ Reader, Oral \& Maxillofacial Surgery, Peoples Dental Academy, Bhopal (M.P.), India
}

\begin{abstract}
India has the third largest HIV epidemic in the world. The HIV/AIDS epidemic constitutes one of the most formidable challenges to development and social progress. Antiretroviral therapy (ART) is the most common treatment provided to HIV/AIDS patients. Oral lesions strongly associated to HIV/AIDS. Moreover, no evidential record of any study on AIDS patients attending retro viral therapy at Bhopal is present. So, a pioneer attempt has been made to assess the oral health status \& treatment needs of patients attending anti-retro viral therapy in ART cell, G.M.C Bhopal.
\end{abstract}

Material \& methods: A Descriptive cross-sectional study design was employed. Total 320 patients were examined. All patient who reported in unit, since last 3 year were included in the study. data was collected and recorded using printed proforma. Consisted of WHO Oral Health Assessment form 1997 . The collected data were coded, and statistical analysis was carried out using Statistical Package of Social Science (SPSS Version 22) chi-square, T test, unpaired T test, ANOVA is used. The statistical significance was fixed at 0.05 .

Results: A total of 320 study subjects were examined, 202(63.1\%) were male and 118(36.8\%) were females. 124(38.75\%) had ulceration erosion on vermillion border. Total 145(45.3\%) AIDS Patients had TMJ symptoms of pain. 7(2.1\%) had malignant tumor, 11(3.2\%) had leukoplakia, 18(5.8\%) had lichen plannus, 98(30.06\%) had ulceration, $67(20 \%)$ had candidiasis, $57(17.8 \%)$ had abscess. Total periodontal disease prevalence was $78.8 \%$,. Mean DMFT was 3.50 $\pm 2.18,50(15.6 \%)$ had dental trauma. Overall, one surface filling, two surface filling, extraction \& pulp care restorations were most frequent treatment need.

Conclusion: The study shows that HIV positive patients have poor oral health status. The use of antiretroviral drugs further depletes their oral health and is responsible for development of periodontal diseases, dental caries and oromucosal lesions.

\section{Introduction}

India has the third largest HIV epidemic in the world. In 2016, HIV prevalence in India was an estimated $0.3 \%$. This figure is small compared to most other middle-income countries but because of India's huge population ( 1.324 billion) this equates to 2.1 million people living with HIV. In the same year, an estimated 62,000 people died from AIDSrelated illnesses [1]. The HIV/AIDS epidemic constitutes one of the most formidable challenges to development and social progress. The epidemic exacerbates poverty and inequality and increases the burden on the most vulnerable people in society i.e. the elderly, the women, children and the poor.

Antiretroviral therapy (ART) is the most common treatment provided to HIV/AIDS patients. Mostly it consists of two nucleoside reverse transcriptase inhibitors (NRTI) along with one non- nucleoside inhibitor (NNRTI) or one protease inhibitor (PI) [2] It is generally agreed that the recognition of some oral manifestations of HIV is of great importance, as these are among the earliest clinical manifestations and have been shown to be highly predictive markers of severe immunosuppression and disease progression [3].
Oral lesions strongly associated to HIV/AIDS include oral candidiasis, oral hairy leukoplakia, periodontal diseases, oral warts, Kaposi sarcoma and recurrent oral ulcers [4]. Oral mucosal lesions have been reported to be decreased after ART [5].

Before the HAART era, some oral lesions including oral candidiasis (OC) and oral hairy leukoplakia (OHL) were commonly observed among HIV-infected individuals both in developed and developing countries [6-11]. The introduction of HAART has contributed to a global reduction in oral lesions in adults and children [12-14]. A decreased prevalence of HIV-related oral lesions of $10-50 \%$ following the advent of HAART has been reported [15-17]. However, the impact of long-term use of HAART on oral health status of HIV-infected subjects is poorly documented.

${ }^{\star}$ Correspondence to: Vijayta Sharva, Senior Lecturer, Public Health Dentistry, Peoples Dental Academy, Bhopal (M.P.), India, E-mail: vijaytasharva@gmail.com

Key words: antiretroviral therapy (ART), hiv Patient, oral health status

Received: June 30, 2019; Accepted: July 18, 2019; Published: July 29, 2019 
Vishnu V (2019) Oral health status \& treatment needs of patient attending anti retro-viral therapy among HIV patient in Government Medical College, Bhopal - A cross-sectional study

There are vast literature on studies conducted on HIV/AIDS patients globally but there are a very scarce studies conducted on patients undergoing anti-retro viral therapy \& shows its association with oral health. Moreover, no evidential record of any study on AIDS patients attending retro viral therapy at Bhopal is present. So, a pioneer attempt has been made to assess the oral health status \& treatment needs of patients attending anti-retro viral therapy in ART cell, G.M.C Bhopal. Which is one of the biggest ART cell in the central India.

\section{Material and methods}

A Descriptive cross-sectional study design was employed in the present work. The study was conducted among HIV positive patients visiting the ART center at Gandhi Medical College and Hospital, Bhopal City, Madhya Pradesh, for HAART treatment. The study was approved by the Institutional Ethics Committee. The study population who were present on the day of examination was included in the study. Those patients who were not willing to participate were excluded from the study. Total 320 patients were examined. All patient who reported in unit, since last 3 year were included in the study. All information about the patients and their identity was anonymous. Subjects were given both verbal and written information about the nature of the study, and written consent was obtained. Subjects were allowed to leave the study at any time during the procedures.

In this study the data was collected and recorded using printed proforma. Consisted of WHO Oral Health Assessment form 1997 [18]. All the patients were informed about the purpose of this study, and information regarding demography, oral complaints, and medical and drug history was recorded. The patients were evaluated for both extraoral and intraoral lesions on the chair under artificial light using disposable instruments, double gloves and mask, and protective eyewear.

The collected data were coded, and statistical analysis was carried out using Statistical Package of Social Science (SPSS Version 22) chi-square, $\mathrm{T}$ test, unpaired $\mathrm{T}$ test, ANOVA is used. The statistical significance was fixed at 0.05 .

\section{Results}

A total of 320 study subjects were examined, 202(63.1\%) were male and $118(36.8 \%)$ were females. Age range was $132(41.3 \%)$ were $31-45$ year old, 108(33.7\%) were $15-30$ year old and $80(25 \%)$ were $46-60$ year old. There was statistically no significant difference in distribution of AIDS Patients according to age \& gender $(\mathrm{P}=0.62)$ (Figure 1).

Out of 320 AIDS Patients 50(15.6\%) subjects had normal extra oral appearance and Maximum 124(38.75\%) had ulceration erosion on vermillion border and $84(26.2 \%)$ had erosion on nose, cheeks, chin. It was seen more in male worker as compare to male as well as it was seen more in 31-45 year old patients. There was statistically highly significant difference in extra oral findings according to age \& gender $(\mathrm{P}=0.001 \& \mathrm{P}=0.002)$ (Figure 2).

Total 145(45.3\%) AIDS Patients had TMJ symptoms of pain. 89(27.8\%) male \& 56(17.5\%) females' patients had symptoms of pain. Tenderness was seen in total $38(11.8 \%)$ and reduced jaw mobility was seen in $4(1.2 \%)$. According to age and gender there was significant difference in TMJ tenderness and reduced jaw mobility signs $(\mathrm{P}=0.001$ $\& \mathrm{P}=0.05$ ) (Figure 3).

Out of 320 AIDS Patients, 62(19.3\%) reported with no abnormal oral mucosal condition \& remaining $7(2.1 \%)$ had malignant tumor,

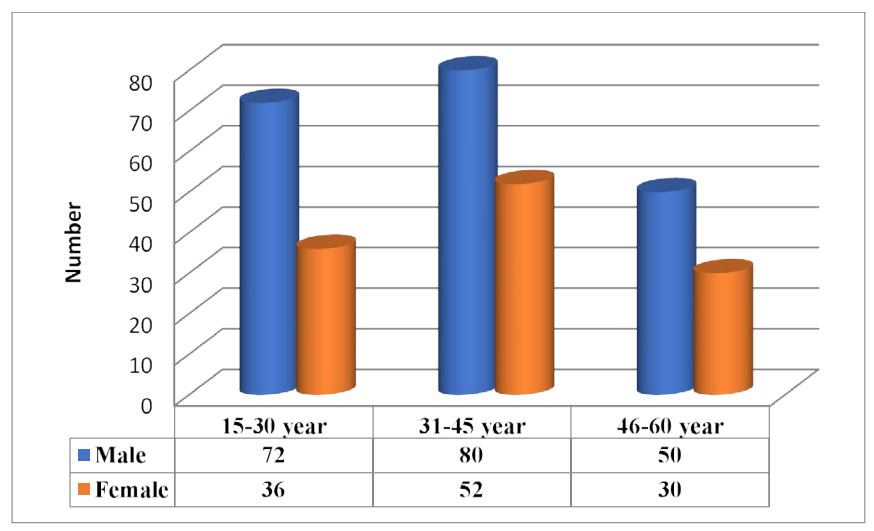

Figure 1. Demographic Distribution of AIDS Patients according to age \& gender

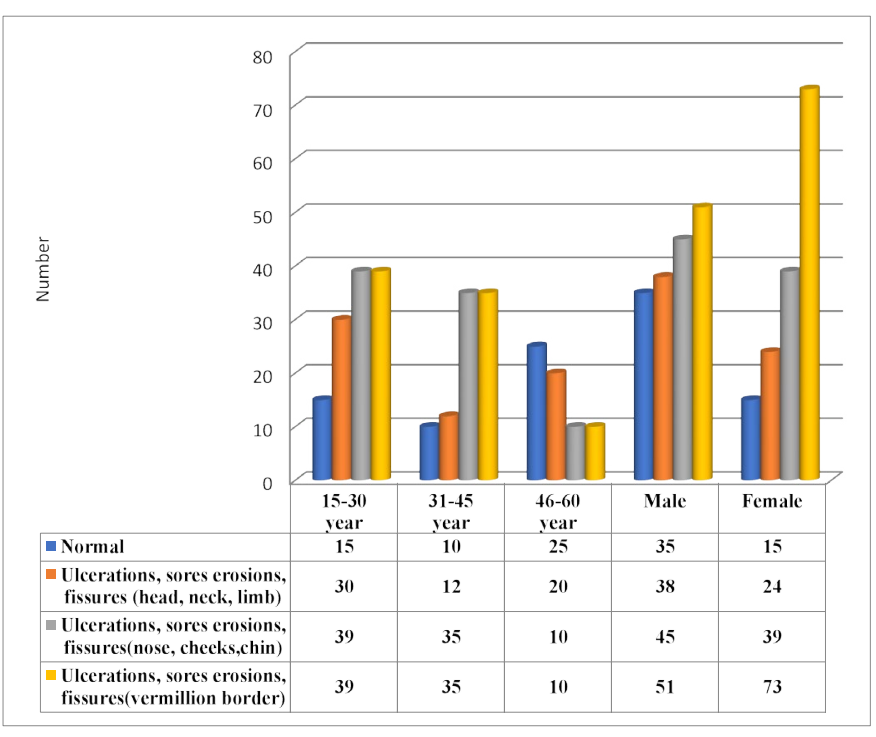

Figure 2. Distribution of Extra oral finding among AIDS Patients according to age \& gender

11(3.2\%) had leukoplakia, 18(5.8\%) had lichen plannus, 98(30.06\%) had ulceration, 67(20\%) had candidiasis, 57(17.8\%) had abscess. Candididias \& Abscess were seen more in male as compare to female and oral mucosal condition were more prevalent among 15-30 \& 31-45 year old patients. It shows statistically significant difference in distribution of oral mucosal condition according to age \& gender $(\mathrm{P}=0.005 \& \mathrm{P}=0.03)$ (Table 1).

Total periodontal disease prevalence was $78.8 \%$ Among 320 AIDS Patients 68(21.2\%) had healthy gingiva, 43(13.4\%) had bleeding problem, 66(20.6\%) had calculus, $71(22.1 \%)$ had shallow pocket and 72(22.5\%) had deep pocket. Periodontal Disease were more prevalent among male as compared to females and it was more prevalent among 31-45 year old patients. There was statistically significant difference in prevalence of periodontal disease among AIDS Patients according to age \& gender $(\mathrm{P}=0.001)$ (Table 2).

Mean dental caries experiences were increasing with the rise in age. Mean DMFT was seen highest in 46-50 year age groups. Mean DMFT was $3.50 \pm 2.18$ in male as compare to $2.58 \pm 3.00$ in females. Total mean DT was $2.99 \pm 0.80$, mean MT was $2.74 \pm 1.1$, mean FT was $0.92 \pm 0.21$ and total mean DMFT was 3.04 \pm 1.65 . Mean dental caries experiences shows statistically highly significant according to age group\& gender $(\mathrm{P}<0.05)$ (Figure 4). 
Vishnu V (2019) Oral health status \& treatment needs of patient attending anti retro-viral therapy among HIV patient in Government Medical College, Bhopal - A cross-sectional study

Table 1. Distribution of oral mucosal condition among AIDS Patients according to age \& gender

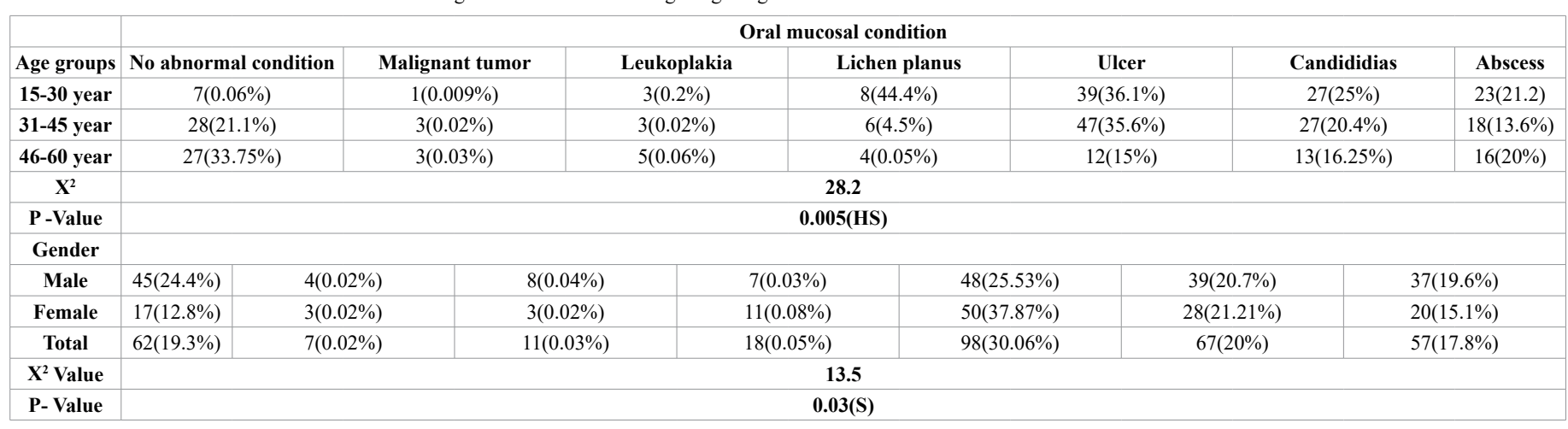

Table 2. Prevalence of periodontal disease among AIDS Patients according to age \& gender

\begin{tabular}{|c|c|c|c|c|c|c|c|}
\hline Age groups & $\begin{array}{c}\text { Healthy } \\
0\end{array}$ & $\begin{array}{c}\text { Bleeding } \\
1\end{array}$ & $\begin{array}{c}\text { Calculus } \\
2\end{array}$ & $\begin{array}{c}\text { Shaollow pocket } \\
3\end{array}$ & $\begin{array}{c}\text { Deep pocket } \\
4\end{array}$ & Chi-Squre Value & P-Value \\
\hline 15-30 year & $38(55.8 \%)$ & $15(34.8 \%)$ & $26(39.3 \%)$ & $18(25.3 \%)$ & $11(15.2)$ & \multirow{3}{*}{33.2} & \multirow{3}{*}{0.001 (HS) } \\
\hline 31-45 year & $18(26.4 \%)$ & $15(34.8 \%)$ & $26(29.3 \%)$ & $38(53.5$ & $35(48.6 \%)$ & & \\
\hline 46-60 year & $12(17.6 \%)$ & $13(30.2 \%)$ & $14(21.2 \%)$ & $15(21.1 \%)$ & $26(36.1 \%)$ & & \\
\hline \multicolumn{8}{|l|}{ Gender } \\
\hline Male & $28(41.1 \%)$ & $30(69.6 \%)$ & $36(54.5 \%)$ & $46(64.7 \%)$ & $62(86.1 \%)$ & \multirow{2}{*}{33.4} & \multirow{2}{*}{0.001 (HS) } \\
\hline Female & $40(58.8 \%)$ & $13(30.2 \%)$ & $30(45.4 \%)$ & $25(35.2 \%)$ & $10(13.8 \%)$ & & \\
\hline Total & $68(21.2 \%)$ & $43(13.4 \%)$ & $66(20.6 \%)$ & $71(22.1 \%)$ & $72(22.5 \%)$ & & \\
\hline
\end{tabular}

Overall one surface filling, two surface filling, extraction \& pulp care restorations were most frequent treatment need. One surface filling was needed in $2.145 \pm 1.06$ teeth among male and $2.01 \pm 1.30$ teeth among females, two surface filling was needed in $0.767 \pm 1.04$ teeth among male and $0.84 \pm 1.07$ among females. Pulp care \& Restoration was needed in $0.40 \pm 0.49$ among male and and $0.57 \pm 1.09$ among females. Result shows statistically not significant difference according to gender in one and two surface feeling treatment need while for crown, pulp care and extraction there was statistically significant difference (Figure 5).

Out of 320 AIDS patients, 200(62.5\%) did not have any prosthesis, $47(14.6 \%)$ had one unit prosthesis \& $73(22.8 \%)$ had multiunit prosthesis in upper arch. $79(24.6 \%)$ had one unit \& 64(20\%) had multiunit prosthesis in lower arch. It shows statistically significant difference in upper arch and lower arch according to age $(\mathrm{P}=0.001)$ (Figure 6).

Out of 320 AIDS patients, 50(15.6\%) had dental trauma. Incidence of trauma was more among male i.e 46(14.3\%) and among female it was $4(1 \%)$. There was statistically significant difference in incidence of trauma according to age and gender (Figure 7).

\section{Discussion}

The current cross-sectional study was conducted among 320 patients receiving antiretroviral therapy in Gandhi Medical College, Bhopal. To assess their oral health status and treatment needs. Because oral cavity is an important and frequently undervalue source of diagnostic and prognostic information in patients with HIV infection [19]. Oral disease is frequently the first indicator of progression of symptomatic disease of HIV infection [20].

Most of the patients 202(63.1\%) were male while 118(36.8\%) were females. This finding signifies that HIV/AIDS is more commonly reported in males than females in India. Similarly, Ceena E Denny et al. [21] conducted a study on ART patients reporting that more male patients were affected with HIV/AIDS as compared to females, which was also similar to the results of Bravo et al. [22] where male predominance was observed, further confirmed by the reports of

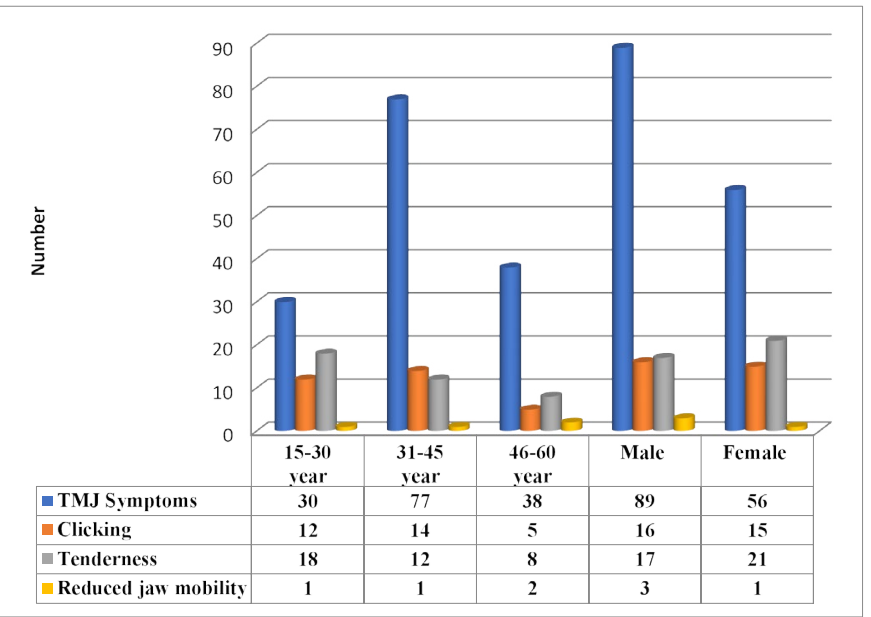

Figure 3. Distribution of the tempromandibular joint symptoms \& sign among AIDS Patients according to age \& gender

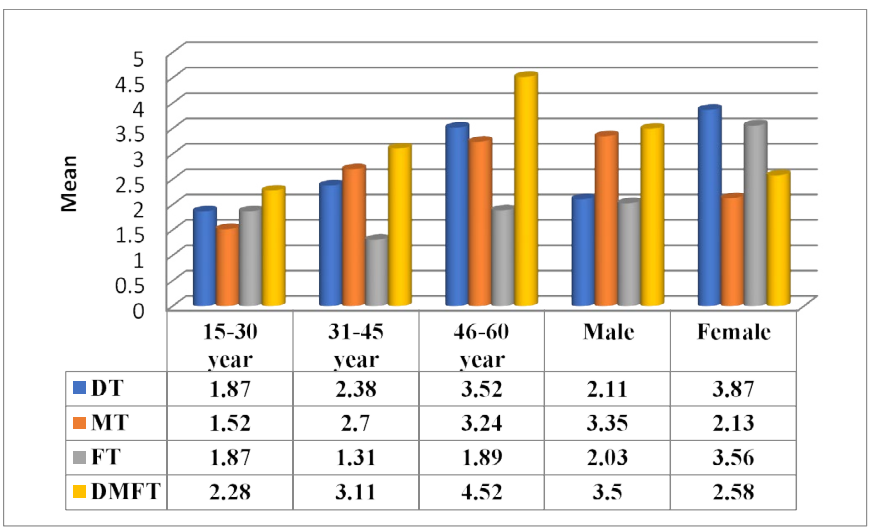

Figure 4. Mean Dental caries experience (DT,MT,\& DMFT) among AIDS Patients according to age \& gender 


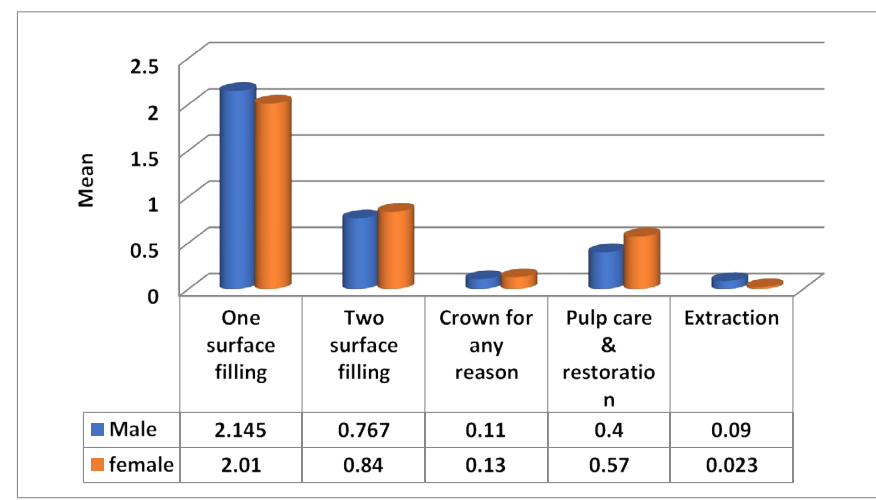

Figure 5. Distribution of overall treatment among AIDS Patients according to gender

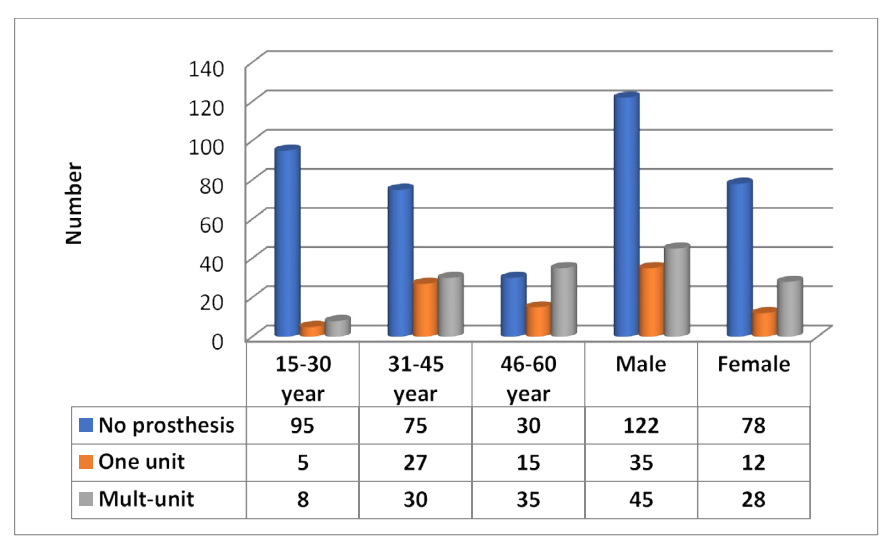

Figure 6. Distribution of prosthetic status in upper arch among AIDS Patients according to age \& gender

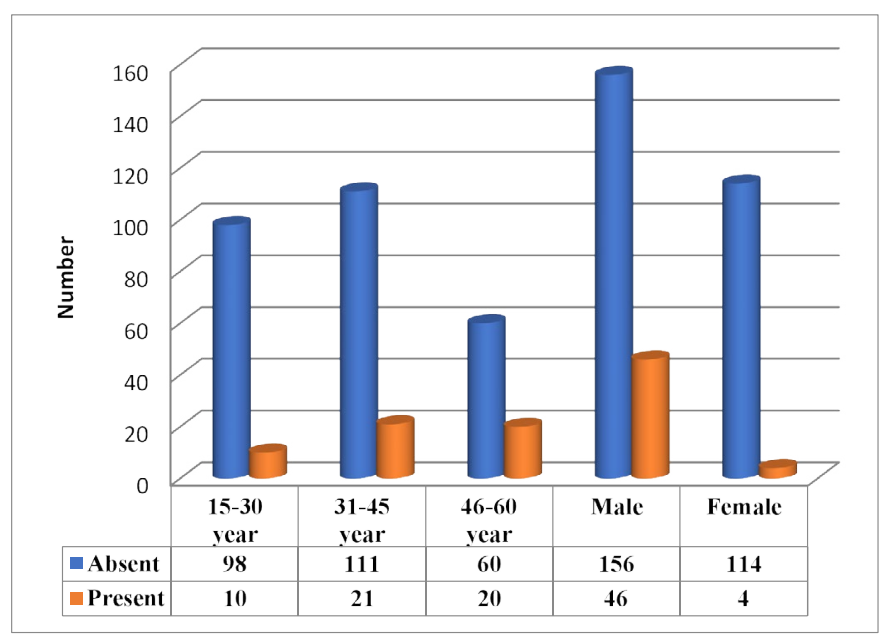

Figure 7. Distribution of trauma among AIDS Patients according to age $\&$ gender

Ashish Bodhade et al. [23] and Ranganathan et al. [24] who noted the same results. The most common age group of the patients in the present study was 31-45 years. Finding corresponds with the fact that sexually active age group is more prone to acquire HIV infection. Mathur N [25] also reported similar findings.

In the present study, the subjects that were examined under antiretroviral therapy the total mean DMFT was 3.04 \pm 1.65 . Mean dental caries experience shows highly statistically significant results according to age \& gender. Similarly, Rezaei-Soufi et al. [26] found total mean DMFT to be $15.14 \pm 6.09$. This, highly significant result is due to lack of awareness for oral health furthermore ART drugs also depletes oral health by affecting salivary flow which leads to high caries incidence in these patients.

In the present study prevalence of periodontal disease was reported to be $71.2 \%$ which was seen to be similar when compared to a study conducted, Sandeep et al. [27] conducted a study on HIV patients which reported that more than $50 \%$ of patients had periodontal disease. Periodontal diseases may be the first clinical sign of human immunodeficiency virus (HIV)-infection. Since the immune suppression and subsequent susceptibility may alter the responses of the oral tissues as well as the microflora hence there is high prevalence of periodontal disease. In addition to this, factors such as sideffects of ART drugs, tobacco abuse, oral health negligence contribute to worsen the periodontal health of these patients.

The present study reported that $80.53 \%$ of patients attending ART had oral mucosal lesions which was similar to the results of a study conducted by Duggal et al. [28] in South Africa where $51.1 \%$ patients receiving ART therapy had oral mucosal lesion. Higher frequency of oral lesions in the present study may be due to the fact that most patients in this study had low CD4+lymphocyte count, which is considered as the state of advanced immunosuppression according to WHO immunological classification system [29].

Antiretroviral therapy has changed the course of HIV disease and improved quality of life in HIV patients but the patients may also experience adverse effects .The orofacial adverse effects of HAART including oral ulcers, xerostomia, mucositis, hyperpigmentation, erythema multiforme (EM), cheilitis, perioral paresthesia, angioedema, and taste alteration have been reported [27].

\section{Conclusion}

In conclusion, the study shows that HIV positive patients have poor oral health status and also have less awareness about oral health. The use of antiretroviral drugs further depletes their oral health and is responsible for development of periodontal diseases, dental caries and oromucosal lesions. Maximum patient had ulceration erosion on vermillion border, TMJ symptoms of pain. Overall one surface filling, two surface filling, extraction \& pulp care restorations were most frequent treatment need.

\section{Recommendations}

Thus one should be aware about them about the importance of good oral health as well a dentist should be placed in all the ART CENTERS to give oral health education \& to escalate oral health related quality of life\& prevention of oral infection for health longevity among this immune suppressive patient. These dental professionals should also be well trained enough to treat \& attend to oral health issues for tertiary ill patients. Further studies should be undertaken in various states of India, specifically now, in the era of anti-retroviral therapy to find out the changing prevalence of oral diseases and oral health status and treatment needs.

\section{Conflicts of interest}

The authors declare that there is no conflict of interests regarding the publication of this paper.

\section{Authors' contribution}

All the authors have read and approved the final paper. 


\section{Acknowledgment}

The authors would like to extend their thanks to the senior medical officer, ART plus cell, Gandhi Medical College, Bhopal. for providing facilities for free dental check-up for patients living with HIV/AIDS.

\section{References}

1. UNAIDS (2017) Data Book[pdf] available at www.unaids.org/en/resouces/ documents/2017/2017_data_book

2. World Health Organization (WHO), (2013) Consolidated guidelines on the use of antiretroviral drugs for treating and preventing HIV infection: summary of key features and recommendations.

3. Narani N, Epstein JB (2001) Classification of oral lesions in HIV infection. J Clin Periodontol 28(2): 135-147.

4. Shiboski CH, Patton LL, Webster-Cyriaque JY, Greenspan D, Traboulsi RS, et al. (2009) The Oral HIV/AIDS Research Alliance: updated case definitions of oral disease endpoints. J Oral Pathol Med 38: 481-488.

5. Umadevi KM, Ranganathan K, Pavithra S, Hemalatha R, Saraswathi TR, et al. (2007) Oral lesions among persons with HIV disease with and without highly active antiretroviral therapy in southern India. J Oral Pathol Med 36: 136-141.

6. Silvermann S, Jr, Migliorati CA, Lozada-Nur F, Green-span D, Conant MA (1986) Oral findings in people with or at a high risk for AIDS; a study of 375 homosexual males. $J$ Am Dent Assoc 112: 187-92.

7. Ramirez V, Gonzalez A, de la Rosa E (1990) Oral lesions in Mexican HIV-infected patients. J Oral Pathol Med 19: 482-5.

8. Tukutuku K, Muyembe-Tamfum L, Kayembe K, Odio W, Kandi K, Ntumba M (1990) Oral manifestations of AIDS in a heterosexual population in a Zaire hospital. J Oral Pathol Med 19: 232-234.

9. Laskaris G, Hadjivassiliou M, Stratigos J (1992) Oral signs and symptoms in 160 Greek HIV-infected patients. J Oral Pathol Med 21: 120-3.

10. Glick M, Muzyka BC, Lurie D (1994) Oral manifestations associated with HIV-related disease as markers for immune suppression and AIDS. Oral Surg Oral Med Oral Pathol 77: 344-349.

11. Nittayananta W, Chungpanich S (1997) Oral lesions in a group of Thai people with AIDS. Oral Dis 3(Suppl. 1): 1-5

12. Patton LL, McKaig R, Strauss R, Rogers D, Eron JJ., Jr (2000) Changing prevalence of oral manifestations of human immune-deficiency virus in the era of protease inhibitor therapy. Oral Surg Oral Med Oral Pathol Oral Radiol Endod 89: 299-304.

13. Nokta M (2008) Oral manifestations associated with HIV infection. Curr HIV / AIDS Rep 5: 5-12

14. Miziara ID, Weber R (2008) Oral lesions as predictors of highly active antiretroviral therapy failure in Brazilian HIV-infected children. J Oral Pathol Med 37: 99-106.
15. Ceballos-Salobrena A, Gaitan-Cepeda LA, Ceballos-Garcia L, Lezama-Del Valle D (2000) Oral lesions in HIV / AIDS patients undergoing highly active antiretroviral treatment including protease inhibitors: a new face of oral AIDS? AIDS Patient Care STDS 14: 627-35.

16. Tappuni AR, Fleming GJ (2001) The effect of antiretroviral herapy on the prevalence of oral manifestations in HIV-infected patients: a UK study. Oral Surg Oral Med Oral Pathol Oral Radiol Endod 92: 623-8.

17. Ramirez-Amador V, Esquivel-Pedraza L, Sierra-Madero J, Anaya-Saavedra G, Gonzalez-Ramirez L, Ponce-de-Leon S (2003) The changing clinical spectrum of human immunodeficiency virus (HIV)-related oral lesions in 1000 consecutive patients: a 12-year study in a referral center in Mexico. Medicine (Baltimore) 82: 39-50.

18. World Health Organization, Oral Health Survey: BasicMethods, World Health Organization, Geneva, Switzerland, 4th edition,1997.

19. Iain LC, Hamburger J (2000) The significance of oral health in HIV disease. Sexually Transmitted Infec-tions 76: 236-243.

20. Butt FMA, Vaghela VP, Chindia ML, Mandalia K (2001) Oral manifestation of HIV AIDS in Kenyan Provincial Hospital. East African Medical Journal 78: 389-401.

21. Ceena E Denny, John Ramapuram, TS Bastian (2016) Oral Lesion in HIV/AIDS patients on a highly active antiretroviral Therapy. World Journal of Dentistry 7(2): 9599.

22. Bravo IM, Correnti M, Escalona L, Perrone M (2006) prevalence of oral lesions in HIV patients related to CD4 cell count and viral load in a Venezuelan population. Med oral patol cir bucal 11(1): 33-39.

23. Bodhade AS, Ganvir SM, Hazarey VK (2011) Oral manifestations of HIV infection and their correlation with CD4 count. J Oral Sci 53(2): 203-211.

24. Rangnathan K, Reddy BV, kumarasamy N (2000) Oral lesions and conditions associated with human immunodeficiency virus infection in 300 south Indian patients. Journal of Oral Diseases 6(3): 152-157.

25. Mathur N (2013) Correlation between Oral Manifestations and CD4+ count of HIV+ve patients. J Evolu of Med and Dent Sci 12: 4419-4424.

26. Rezaei-Soufi L, Davoodi P, Abdolsamadi HR (2014) Dental caries prevalence in human immunodeficiency virus infected patients receiving highly active anti- retriviral therapy in kermanshah, Iran. cell $J 16(1)$ : 73-8.

27. Sandeep K,Prashant Mishra, Shilpa Warhekar (2014) Oral health status and oromucosal lesions in patients living with hiv/aids in India; A comparative study. AIDS Research and Treatment 2; 1-4.

28. Duggal MS, Abbudiak H, Dunn C (2001) Effect of CD4+ lymphocyte count, viral load, and duration of taking anti-retroviral treatment on presence of oral lesions in a sample of south African children with HIV+/AIDS. European Journal of Arch Paediatr Dent 11: $242-246$.

29. Hegde, MN, Hegde ND, Malhotra A (2012) Prevalence of oral lesions in HIV infected adult population of Mangalore, Karnataka, India. BioDiscovery 4: 3.

Copyright: (C2019 Vishnu V. This is an open-access article distributed under the terms of the Creative Commons Attribution License, which permits unrestricted use, distribution, and reproduction in any medium, provided the original author and source are credited. 